\title{
Nutritional screening tools in daily clinical practice: the focus on cancer
}

\author{
Michèle Leuenberger • Silvia Kurmann • Zeno Stanga
}

Received: 14 April 2009 /Accepted: 15 December 2009/Published online: 20 January 2010

(C) Springer-Verlag 2010

\begin{abstract}
Introduction Malnutrition is a common and under-recognized problem in cancer patients. It has been correlated to a large number of physical, psychological, and clinically relevant adverse effects in oncology patients, including impaired tolerance to anticancer therapy, adverse reactions, and reduced quality of life. Consequently, tailored strategies to identify patients at nutritional risk are essential to implement nutritional support effectively and to reduce cancer morbidity. Purpose of a nutritional screening tool A screening tool should be an easy, standardized, rapid, noninvasive, and cost-effective diagnostic tool to identify cancer patients at nutritional risk in daily clinical practice. If patients at risk for malnutrition are identified early, many cases may be treated or prevented, with beneficial effects on patient outcome and subsequent reductions of health care costs. Screening tools This article discusses the Malnutrition Universal Screening Tool, the Nutritional Risk Screening, the Mini Nutritional Assessment-Short Form ${ }^{\circledR}$, the scored Patient-Generated Subjective Global Assessment (PG-SGA), and the Malnutrition Screening Tool (MST) in an oncology setting.

Conclusions Clinical institutions should implement an appropriate and validated screening tool and assessment protocol, which should contain an action plan. To date, the
\end{abstract}

\footnotetext{
M. Leuenberger $\cdot$ S. Kurmann $\cdot$ Z. Stanga $(\bowtie)$

Division of Endocrinology, Diabetes and Clinical Nutrition, Department of General Internal Medicine,

Bern University Hospital,

3010 Bern, Switzerland

e-mail: zeno.stanga@insel.ch

Z. Stanga

Department of General Internal Medicine,

University of Bern and Bern University Hospital,

Bern, Switzerland
}

MST and the PG-SGA are the best validated screening tools for use in oncology patients. The PG-SGA is an assessment tool with screening components, whereas the MST is a pure screening tool and, therefore, quick and easy to use for trained as well as untrained staff. Further validation of all nutrition screening tools is needed, as well as further research to evaluate the benefits of nutrition screening and support with regard to outcomes.

Keywords Nutritional screening tools $\cdot$ Daily clinical practice $\cdot$ Cancer $\cdot$ Oncology patients $\cdot$ Malnutrition

\section{Introduction}

Decline in nutritional status and continuing weight loss may have deleterious consequences for oncology patients. The prevalence of cancer-related malnutrition ranges from $30 \%$ to $64 \%$ in inpatients and is related to an increased risk for adverse clinical outcome [1-7], poor quality of life, and lower survival rates [8-10]. In addition, as many as $20 \%$ of cancer patients die from the effects of malnutrition rather than from the malignancy [11]. Nutritional status tends to deteriorate during the course of hospitalization [12] and malnutrition is associated with increased morbidity and mortality, prolonged hospital stay, and increased health care costs $[13,14]$. Moreover, malnutrition worsens the responsiveness and the tolerance to anticancer therapy [15]. On the other hand, early and adequate provision of nutritional support for those identified as malnourished has been demonstrated to improve outcome $[16,17]$. It is, therefore, essential that nutritional issues be addressed at the time of diagnosis and throughout the course of cancer care.

Proactive nutritional screening and intervention are the cornerstones of success in preventing symptoms of malnu- 
trition. If patients at risk for malnutrition are identified early, they can be treated or malnutrition may even be prevented. The medical staff in charge of a patient should perform the nutritional risk screening to identify nutritionrelated problems and to solve them with an interdisciplinary approach. One study demonstrated that up to $52 \%$ of malnourished patients were not identified based on their nutritional documentation, suggesting that the problem is commonly overlooked by physicians [12].

First-line strategies must include routine screening and identification of inpatients or outpatients at nutritional risk with the use of a simple and standardized screening tool. There is agreement among international nutrition organizations and accredited health care organizations that routine nutritional screening should be a standard procedure for every patient admitted to a hospital [18-20]. In the absence of formal screening procedures, more than half of the patients at risk for malnutrition do not appear to be identified and/or are not referred for treatment [20]. It is mandatory to identify patients at nutritional risk who can profit from adequate and rapid nutritional support. However, it is a reality that nutritional screenings are not standard care in many institutions. There is no "gold standard" to detect malnutrition. Numerous validated screening tools are available and appropriate for the inpatient and/or outpatient. For clinicians, it is important to know for which population and care setting a tool was designed and to decide if a specific tool may be appropriate for their institution.

\section{Purpose of a nutritional screening tool}

The guidelines of the European Society for Clinical Nutrition and Metabolism (ESPEN) state that nutritional screening should be able to predict the clinical course based on nutritional status and whether patients could benefit from nutritional treatment [19]. Commonly requested criteria for a screening tool are that it is simple to conduct by medical staff or community health care teams and that it is noninvasive as well as quick to perform ( $<5 \mathrm{~min})$. It should not involve calculations or include laboratory data and it should be easily interpretable, inexpensive, and reproducible [21, 22]. Moreover, it should be sensitive enough to detect all or nearly all patients at nutritional risk. There are some advantages in registering disease severity as well as nutritional status, since they interact.

In the community, malnutrition, with or without chronic disease, may be the primary factor determining the mental or physical functioning of an individual, whereas in the clinical setting, disease factors assume greater importance, with disease-associated malnutrition assuming an important even though secondary role [19]. In hospitals, further aspects of a disease have to be considered in combination with nutritional measurements in order to determine whether nutritional support is likely to be beneficial.

The predictive validity of a screening method is of major importance-i.e., that the individual identified to be at risk by the method is likely to benefit from nutritional intervention initiated as a consequence of it. Furthermore, the screening tool must also have a high degree of content validity-i.e., taking into consideration all relevant components of the problem it is meant to solve. In addition, the tool must have high reliability (little inter-observer variation), it must be practical, and it should not contain redundant information. Finally, a screening tool should be linked to a specified protocol for action, such as referral of patients at risk to an expert for more detailed assessment and for determination of the appropriate nutritional intervention. Following nutritional screening, patients at risk should get a more in-depth nutritional assessment. The assessment should be a detailed examination of metabolism, nutritional status, body composition, and functional variables. It is a more extensive process than the screening and it leads to an appropriate nutritional care plan which takes into consideration indications, possible negative effects of malnutrition, and in some cases, special feeding techniques.

\section{Components of nutritional screening}

Screening tools are planned to detect protein and energy malnutrition and/or to predict whether malnutrition is likely to develop or deteriorate under the present and future circumstances affecting the patient. Therefore, screening tools should answer the following four questions [19]:

(a) What is the patient's current condition? Height and weight allow the calculation of the body mass index (BMI). Whenever it is not possible to obtain height and weight, e.g., in severely ill patients, a useful surrogate may be mid-arm circumference [23].

(b) Is the condition stable? Recent weight loss and information on weight changes are obtained from a patient history or from previous measurements in medical records (recent weight loss).

(c) Is the condition likely to get worse? This question may be answered by asking whether food intake has been decreased up to the time of screening (recent food intake).

(d) Is the disease process likely to negatively affect nutritional status? In addition to decreasing appetite, the disease process may increase nutritional requirements due to stress metabolism associated with severe disease.

All screening tools should answer questions a-d for both inpatients and outpatients. A single BMI cut-off value is not 
sufficient for the detection of malnutrition; in particular, knowing if there has been recent weight loss over time helps to identify patients at risk for malnutrition and seems to be the most important single indicator of nutritional status [24]. Therefore, nutritional screening tools should use both BMI and weight loss to predict risk for malnutrition. All those variable parameters are key determinants of cancer patients' quality of life. Ravasco et al. [25] stated that cancer stage and location were the major determinants of patients' quality of life globally, but there were some diagnoses for which the impact of nutritional deterioration $(30 \%)$ combined with deficiencies in nutritional intake $(20 \%)$ may be more important than the stage $(1 \%)$ or location $(30 \%)$ of the cancer. A number of screening tools use further variables, such as gastrointestinal symptoms (nausea, diarrhea, and constipation), pain, and fatigue, which can also impact nutritional status and deterioration. In fact, these parameters have a high specificity $(91.1 \%)$ but a relatively low sensitivity (43.3\%); therefore, more than half of patients who will become malnourished in the future are not categorized as being at high nutritional risk [22].

\section{Screening tools}

The ESPEN recommends the following nutritional screening tools [19]: the Malnutrition Universal Screening Tool (MUST), the Nutritional Risk Screening (NRS2002), and the Mini Nutritional Assessment ${ }^{\circledR}\left(\right.$ MNA $\left.^{\circledR}\right)$ method. This review further includes the Mini Nutritional Assessment-Short Form $^{\circledR}$ (MNA-SF $\left.{ }^{\circledR}\right)$, the Subjective Global Assessment (SGA), the scored Patient-Generated Subjective Global Assessment (PG-SGA), and the Malnutrition Screening Tool (MST).

Malnutrition Universal Screening Tool (MUST) for adults

The purpose of the MUST system is to detect adults who are at risk for malnutrition or who are malnourished on the basis of knowledge about the association between impaired nutritional status, body composition, and physical function (Fig. 1) [26, 27]. It was developed by the Malnutrition Advisory Group, a standing committee of the British Association for Parenteral and Enteral Nutrition $[26,28]$.

The MUST is recommended by ESPEN as the preferred screening tool for patients in the community, which is the setting for which it was primarily developed. In community care, it predicts rate of hospital admissions and the number of visits to general practitioners. Furthermore, it predicts clinical outcome [29]. The MUST is associated with high reproducibility among health care providers and is internally consistent and reliable [28]. It was validated in a
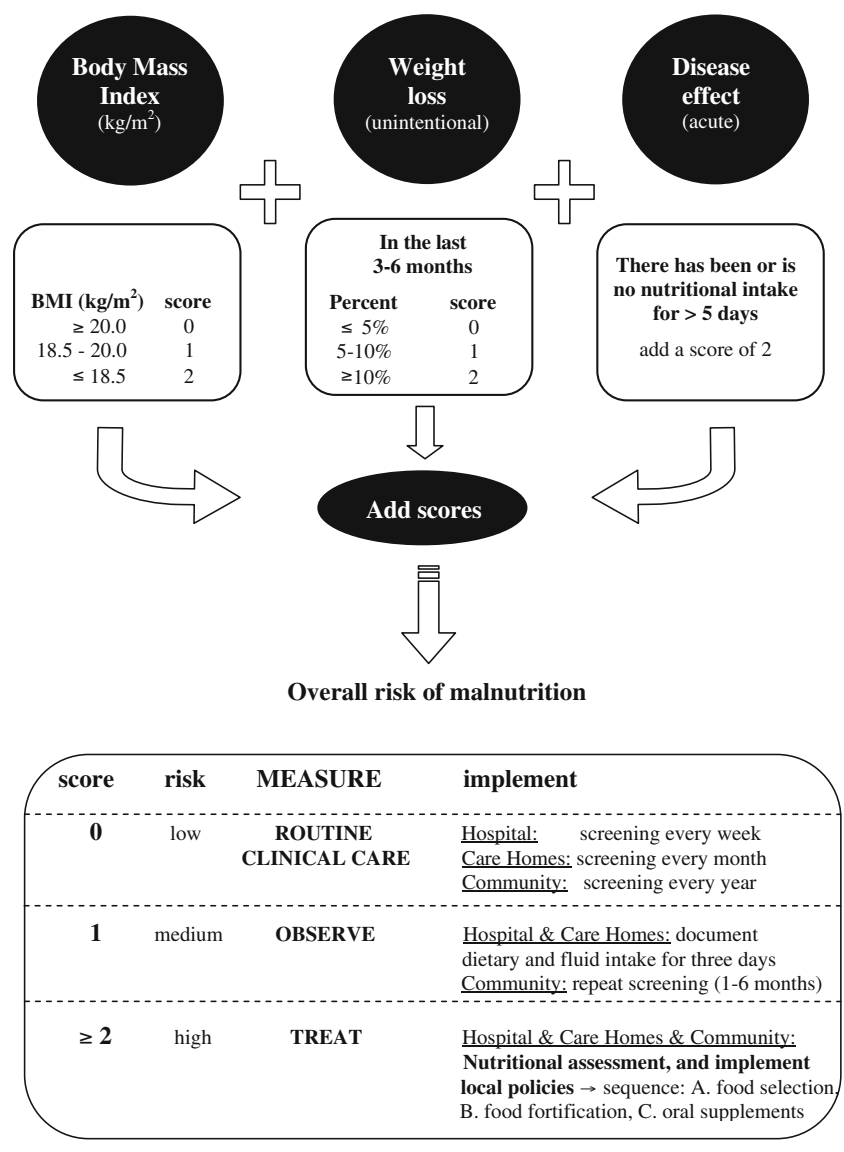

Fig. 1 MUST for adults [26]

range of health care settings (i.e., primary care, home care, acute care, long-term care) by health care providers of various professions and can be applied to adult patients of various ages [27].

Three independent criteria are used by MUST to determine the overall risk for malnutrition: current weight status using BMI, unintentional weight loss, and acute disease effect that induced a phase of nil per os for $>5$ days. Each parameter can be rated as 0,1 , or 2 . Overall risk for malnutrition is established as low (score $=0$ ), medium ( score $=1)$, or high $($ score $\geq 2)$. Each of these three criteria can independently predict clinical outcome, varying by the clinical circumstance, but together the three criteria are better predictors than each by itself [27].

The predictive validity of MUST in the community is based on previous and new studies on the effect of semistarvation/starvation on mental and physical function in healthy volunteers. Moreover, MUST was documented to have a high degree of reliability (low inter-observer variation), with a $\kappa=0.88-1.00$. Its content validity was established by a multidisciplinary working group in its development. Its practicability was documented in a number of studies in different community regions in the United Kingdom [26, 27]. 
Nutritional Risk Screening (NRS-2002)

The NRS-2002 is a screening tool introduced by Kondrup et al. and an ESPEN working group in 2003 (Fig. 2). This tool was validated against 128 controlled nutrition support trials to evaluate whether it was able to distinguish patients with a positive clinical outcome due to nutrition intervention from those who showed no benefit of nutritional support [30]. The ESPEN recommends the NRS-2002 as the preferred screening tool for hospitalized patients (mixed population). It has been well accepted within Europe. It contains all the components of the MUST and, in addition, a grading of severity of disease as a reflection of increased nutritional requirements. It includes four questions as a prescreening for departments with fewer patients at risk. With the prototypes for severity of disease given, it is meant to cover all possible patient categories in a hospital.

The NRS-2002 is an easy-to-use tool that is quick to complete (2-3 min) [31]. In a study of 750 newly admitted patients, it was possible to screen $99 \%$ of the patients. This demonstrates the practicality and usefulness of this tool in hospitalized patients [32]. The NRS-2002 classifies the patient's nutritional status in four categories based on BMI, percentage of recent weight loss, recent change in food intake, and disease severity. Each category can be classified as normal $($ score $=0)$, mild (score $=1$ ), moderate $($ score $=2)$, or severe $($ score $=3)$. The prototypes for severity of disease are:

Score $=1-\mathrm{a}$ patient with chronic disease admitted to the hospital due to complications. The patient is weak

Fig. 2 NRS-2002 [30]

Initial screening: four questions

\begin{tabular}{|l|c|c|}
\hline Is BMI $<20.5 \mathrm{~kg} / \mathrm{m}^{2}$ ? & Yes & No \\
\hline Has the patient lost weight within the last 3 months? & Yes & No \\
\hline Has the patients had a reduced dietary intake in the last week? & Yes & No \\
\hline Is the patient severely ill? (e.g., in intensive therapy) & Yes & No \\
\hline
\end{tabular}

If the answer is 'YES' to any of the questions, perform the full screening.

If the answer is 'NO' to all questions, the patient is re-screened at weekly intervals.

\begin{tabular}{|c|c|c|c|}
\hline Impaired nutritional status & score & $\begin{array}{l}\text { Severity of disease } \\
(\approx \text { increase in requirements })\end{array}$ & score \\
\hline Normal nutritional state & $\mathbf{0}$ & Normal nutr. requirements & $\mathbf{0}$ \\
\hline $\begin{array}{l}\text { Score } 1 \text { (mild) } \\
\text { Weight loss }>5 \% \text { in } 3 \text { months } \\
\quad \text { or } \\
\text { Food intake in preceding week } \\
50-75 \% \text { of normal requirement }\end{array}$ & 1 & $\begin{array}{l}\text { Score } 1 \text { (mild) } \\
\text { - } \text { Hip fracture } \\
\text { - Chronic patients with acute } \\
\text { complications: cirrhosis, COPD } \\
\text { - Chronic hemodialysis, diabetes } \\
\text { - Oncology }\end{array}$ & 1 \\
\hline $\begin{array}{l}\text { Score } 2 \text { (moderate) } \\
\text { Weight loss }>5 \% \text { in } 2 \text { months } \\
\quad \text { or } \\
\text { BMI } 18.5-20.5+\text { impaired general } \\
\text { condition } \\
\quad \text { or } \\
\text { Food intake in preceding week } \\
25-50 \% \text { of normal requirement }\end{array}$ & 2 & $\begin{array}{l}\text { Score } 2 \text { (moderate) } \\
\text { - Major abdominal surgery } \\
\text { - Severe pneumonia } \\
\text { - Hematologic malignancy }\end{array}$ & 2 \\
\hline $\begin{array}{l}\text { Score } 3 \text { (severe) } \\
\text { Weight loss }>5 \% \text { in } 1 \text { month } \\
\quad \text { or } \\
\text { BMI }<18.5+\text { impaired general condition } \\
\quad \text { or } \\
\text { Food intake in preceding week } \\
0-25 \% \text { of normal requirement }\end{array}$ & 3 & $\begin{array}{l}\text { Score } 3 \text { (severe) } \\
\text { - Head injury } \\
\text { - Bone marrow transplantation } \\
\text { - Severe burns } \\
\text { - Intensive care patients (APACHE } \\
\text { score }>10 \text { ) }\end{array}$ & 3 \\
\hline (A) $=$ & & (B) $=$ & \\
\hline
\end{tabular}

Calculation and interpretation of the total score

- Add total $\mathrm{A}+\mathrm{B} \Rightarrow$ ?

- Age if $\geq 70$ years: add 1 to total score above $=$ age-adjusted total score

- $\underline{\text { Score } \geq 3: ~} \rightarrow$ the patient is nutritionally at risk and a nutritional care plan is initiated $\rightarrow$ perform nutritional assessment, and implement local policies

- Score <3: weekly re-screening of the patient. If the patient e.g. scheduled for oncological treatment, a preventive nutritional care plan should be considered to reduce the associated nutritional risk. 
but out of bed regularly. Protein requirements are increased, but can be covered by oral food or supplements in most cases.

Score $=2$ - a patient confined to bed due to illness, e.g., following major abdominal surgery. Protein requirements are substantially increased, but can be covered, although artificial feeding is required in many cases.

Score $=3$ - a patient in intensive care with assisted ventilation, etc. Protein requirements are increased and cannot be covered even by artificial feeding. Protein breakdown and nitrogen loss can be significantly attenuated.

Age contributes one point if the patient is $\geq 70$ years old. The sum of the nutritional score $(0-3)$, severity of disease score $(0-3)$, and age adjustment $(\geq 70$ years: score +1$)$ can range from 0 to 7 . Patients are classified as at no risk with a score $<3$ and as at nutritional risk with a score $\geq 3$.

The NRS-2002 is used to predict outcome based on risk parameters identified in the nutritional assessment. Its predictive validity was documented by applying it in a retrospective analysis of 128 randomized controlled trials, as mentioned above [30]. Subsequently, when applied prospectively in a controlled trial with 212 hospitalized patients who received nutritional intervention based on this screening method, the length of hospital stay was reduced by 6 days among patients with complications who received intervention vs. those who received no nutritional intervention $(p=0.015)$ [33]. Its reliability was validated by interobserver variation among a nurse, a dietician, and a physician, with a $\kappa=0.67$ and with a $\kappa=0.76$ among physicians [3, 30].

Mini Nutrition Assessment ${ }^{\circledR}\left(\mathrm{MNA}^{\circledR}\right)$ and MNA - Short Form $^{\circledR}\left(\mathrm{MNA}^{\circledR} \mathrm{SF}^{\circledR}\right)$

The MNA $^{\circledR}$ is another rapid and efficient nutrition assessment tool (http://www.mna-elderly.com/) [34]. It was developed to assess nutritional status as part of the standard evaluation of elderly patients or otherwise frail individuals in nursing homes and hospitals [35]. The MNA ${ }^{\circledR}$ website gives instructions on the use of this tool [36].The MNA ${ }^{\circledR}$ was validated using two principal criteria: (a) clinical status, which consists of a nutrition assessment conducted independently by physicians trained in nutrition on the basis of the subject's clinical record, and (b) comprehensive nutrition assessment, which includes a complete assessment of anthropometrics, biochemical markers, and dietary intake according to the Survey in Europe on Nutrition and the Elderly, a Concerted Action study [37].

The full MNA ${ }^{\circledR}$ includes 18 items grouped into four rubrics: anthropometric assessment (items B, F, Q, and R), general assessment (items C, D, E, G, H, and I), short dietary assessment (items $\mathrm{A}, \mathrm{J}, \mathrm{K}, \mathrm{L}, \mathrm{M}$, and $\mathrm{N}$ ), and subjective assessment (items $\mathrm{O}$ and $\mathrm{P}$ ). Each answer has a numerical value and contributes to the final score, which reaches a maximum of 30 . A cumulative score on the MNA $^{\circledR}$ of $\geq 24$ indicates a well-nourished state, 17-23.5 indicates a risk for malnutrition, and $<17$ indicates malnutrition. For the MNA ${ }^{\circledR}$ total score, the inter-observer variation was estimated with a $\kappa=0.51$ [38].

The MNA-SF ${ }^{\circledR}$ was developed and validated to allow a two-step screening process in low-risk populations that retains the validity and accuracy of the full $\mathrm{MNA}^{\circledR}$ [39]. The MNA-SF ${ }^{\circledR}$ uses the six strongly correlated items, and the maximum score of the MNA-SF ${ }^{\circledR}$ is 14 . Scores $\geq 12$ indicate satisfactory nutritional status, with no further requirement for intervention. An MNA-SF ${ }^{\circledR}$ screening score $\leq 11$ suggests risk for malnutrition. Confirmation is obtained by completing the full MNA $^{\circledR}$ questionnaire (assessment part). The group of Sieber et al. stated in a trial that the $\mathrm{MNA}^{\circledR}$ is only feasible in $65 \%$ of geriatric patients with acute illness [40]. Compared to this, with the NRS-2002, almost all patients (99\%) could be screened [40]. It takes about 4 min to administer the MNA-SF ${ }^{\circledR}$ and about $15 \mathrm{~min}$ for the full $\mathrm{MNA}^{\circledR}[41]$; in the context of limited human resources, this is a further disadvantage.

\section{Subjective Global Assessment (SGA) and Patient-Generated} SGA (PG-SGA)

The SGA was developed by Detsky et al. in 1987 [42] using a questionnaire that contains medical history and clinical findings items (weight loss, changes in dietary intake, gastrointestinal symptoms, presence of symptoms that can influence nutritional intake, functional capacity, a nutrition-related physical examination, and the clinicians' overall judgment of the patient's nutritional status). The SGA is an assessment tool rather than a screening tool; it has been used in a wide variety of health care settings and has been shown to have superior sensitivity and specificity compared to usual parameters of nutritional assessment, such as albumin [43]. Moreover, the SGA is efficient, costeffective, easy to learn, and showed a high degree of interrater agreement [42]. The negative aspect of this tool is the professional resistance to perform the physical exam and the perception of additional workload. The most timeconsuming aspect of the SGA for the clinician is the patient history section.

In 1994, the SGA was adapted by Ottery to more specifically meet the needs of the cancer patient, with increases in the gastrointestinal symptom section to include the nutritionally determinant symptoms found in the oncology population (PG-SGA) [11, 44]. In addition, the patient can complete the history section to make the process 
more efficient and patient-involved [45]. In 2002, Bauer et al. added scoring and triage components [46]. The resulting tool, the scored PG-SGA, was validated for use in cancer patients [46].

Some studies have shown a close correlation between the scored PG-SGA and weight loss in the previous 6 months [46, 47], length of hospital stay [46], quality of life [47], and energy intake [48]. Moreover, the use of the PG-SGA streamlines nutritional assessment in the clinical oncology setting, involves the patient directly but in an efficient manner, and allows the clinician to spend the limited time available addressing the problems identified rather than gathering information. The PG-SGA simplifies the identification of specific nutritional intervention; it facilitates quantitative outcome data collection, and this tool is specifically useful and validated in a clinical oncology setting. Additionally, the PG-SGA can be used to predict the need of nutritional intervention and more importantly the potential benefit from intensive nutritional support. The tool has the following practical disadvantages:

- Training is required to score the patient-generated section, as well as to complete the clinical assessment portion of the PG-SGA [49, 50];

- The SGA does not allow for the categorization of mild malnutrition and focuses on chronic or established rather than on acute nutritional changes [51, 52];

- The SGA more accurately identifies established malnutrition. Concerning nutritional risk, its sensitivity is suboptimal [53, 54];

- The SGA may just as well represent an index of sickness rather than nutrition [55];

- The PG-SGA includes calculations of percent change in body weight and a nutrition-related physical exam, both of which are time-consuming.

Despite the mentioned drawbacks of the PG-SGA as a screening tool, it is still the tool most widely used and most accepted for nutritional assessment in cancer patients [10, $45,56-58]$.

The current guidelines of the American Society for Parenteral and Enteral Nutrition and ESPEN recommend the SGA for the assessment of nutritional status [18, 59].

\section{Malnutrition Screening Tool (MST)}

The MST, developed by Ferguson et al. in 1999, is a short and easy screening tool (Fig. 3) [22]. MST combines questions regarding appetite and recent unintentional weight loss with the highest specificity and sensitivity at predicting the SGA result scores. The MST has been validated in inpatients and in oncology outpatients receiving radiotherapy [22, 60]. Recently, Isenring et al. compared the tool to the PG-SGA in outpatients receiving chemotherapy and found that the MST was a strong predictor of risk for malnutrition relative to the PG-SGA (see Table 1) [47]. The MST seems to be a quick and easy screening tool which is well-validated in oncology inpatients and outpatients.

\section{Validations of screening tools in the oncology population}

Many tools have been developed to screen for malnutrition, but only a few have been validated in oncology patients. Table 1 provides a survey of key studies addressing malnutrition screening in this setting.

The MUST seems not to be the tool of choice in cancer patients because it lacks sensitivity and specificity for this population [61]. Roulston et al. confirmed this finding, reporting that the MUST failed to identify $61.5 \%$ of patients considered to be at risk for malnutrition (compared with a full nutritional assessment by an oncology dietitian), whereas the MNA and the MST were capable of correctly identifying cancer patients at risk for malnutrition [62]. On the other hand, Amaral et al. stated that the MUST showed the highest agreement with the NRS-2002 in hospitalized cancer patients [4]. Furthermore, it accurately identified patients at risk for longer length of hospital stay [4]. In this study, the MST presented the highest specificity and positive predictive values of $78.3 \%$, but a low sensitivity [4].

According to a study by Kyle et al. [53], which compared various screening tools to the SGA in a mixed hospitalized population, the NRS-2002 was associated with higher sensitivity and specificity and higher positive and negative predictive values than the MUST; the NRS-2002 is a better screening tool than MUST in the hospital setting compared to SGA, but not well-validated in cancer patients. These findings agree with the study of Amaral et al. [4].

The NRS-2002 was validated by several studies in both medical and surgical patients. In a randomized controlled trial in a mixed population $(n=212 ; 19 \%$ oncology patients), Johansen et al. showed a risk for nutritionrelated worsened outcome if untreated [33]. In another international, multicenter trial $(n=5,018$, mixed population; about $20 \%$ oncology patients), an NRS-2002 score $\geq 3$ was shown to be significantly related to longer hospital stay and to higher complication and mortality rates, also after adjustment for confounders [3]. The study by Schiesser et al. demonstrated that the NRS-2002 was successful in predicting postoperative complications in 608 patients undergoing elective gastrointestinal surgery for benign diseases and malignancy (22.3\%) [66]. The authors reported a nutritional risk prevalence of $40 \%$ in the cancer patients. In a recent trial from our research group, we showed that the nutritional risk determined by the NRS2002 is a significant clinical predictor of postoperative 
Fig. 3 MST [22]

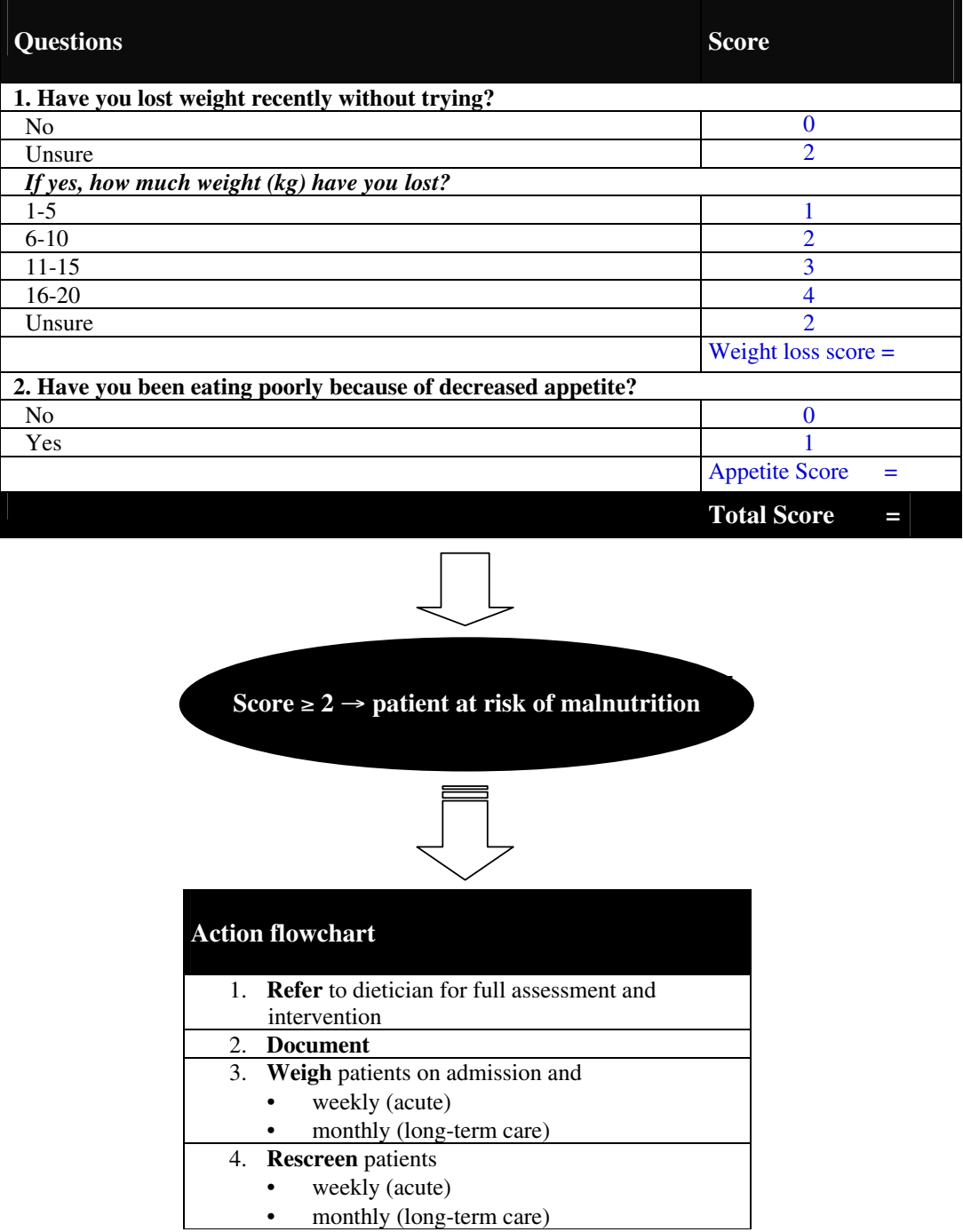

complication rate and shows a positive trend in predicting mortality [63].

Although the $\mathrm{MNA}^{\circledR}$ and the MNA-SF ${ }^{\circledR}$ tools have been used in oncology patients, there is limited evaluation in the oncology population $[49,56,67]$. There are a number of questions that relate to dietary intake, but none of them consider nutritional impacts specific to cancer. Moreover, there are no intervention guidelines. Furthermore, the sensitivity of the $\mathrm{MNA}^{\circledR}$ in analyzing an unintentional weight loss of $>10 \%$ over 3 months was merely 33\% [56], and the positive predictive value in oncology patients was limited, at 59\% [49].

Read et al. compared the MNA ${ }^{\circledR}$ and the PG-SGA in an oncology setting. Both tools were able to correctly classify patients as malnourished, although the $\mathrm{MNA}^{\circledR}$ lacked specificity [49]. This indicates that the MNA ${ }^{\circledR}$ categorizes some patients as requiring nutritional support when actually they do not. The MNA ${ }^{\circledR}$ contents determinants of nutritional status, which included, for example, the use of more than three medications and the number of full meals taken per day. If patients receive more than three medications or eat fewer than three full meals, which is frequently the case for oncological patients, they are penalized with points deducted from the score and are wrongly categorized as being at risk for malnutrition or malnourished.

Bauer et al. compared the MNA ${ }^{\circledR}$ and the NRS-2002 in a geriatric population with acute illness at hospital admission and stated that the MNA ${ }^{\circledR}$ appears to be more appropriate for the community-dwelling elderly [40]. The NRS-2002 offers advantages in the hospital setting (e.g., simple and quicker).

In addition, the $\mathrm{MNA}-\mathrm{SF}^{\circledR}$ requires further validation and reliability testing in oncology patients. The current diagnostic indicators of this tool may need further adaptation for cancer patients. The PG-SGA is the most studied and most commonly accepted system for an accurate nutritional assessment of oncology patients. However, it is an assessment rather than a quick and easy screening tool. It 


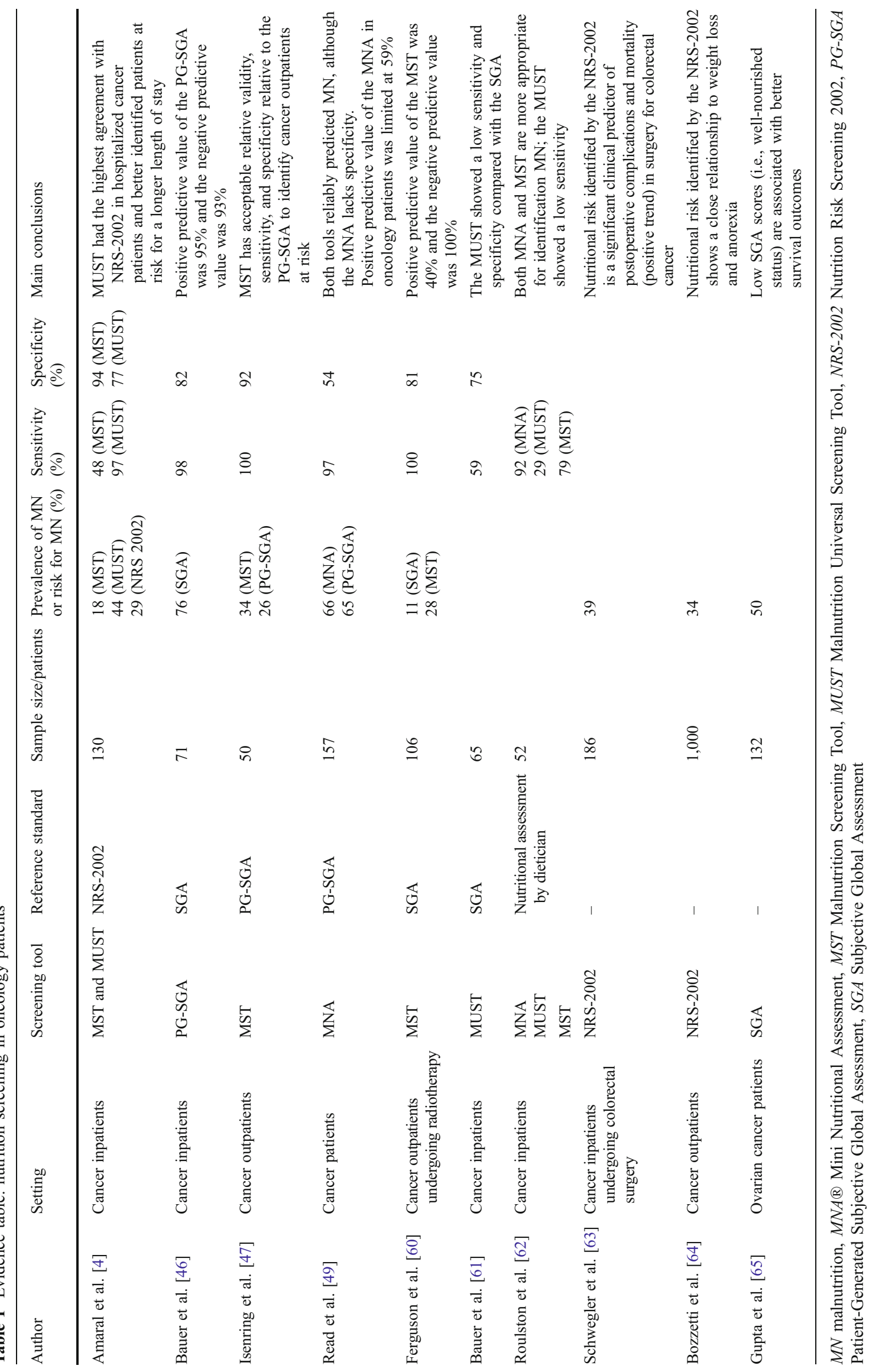


relies on patient literacy, is more time-consuming, and requires more examiner training than the MST, MNA, MUST, and the NRS-2002. Nevertheless, the PG-SGA is deemed to be the "gold standard" in oncology patients. The MST has been validated in various studies [4, 47, 60, 62]. It is an appealing choice to screen cancer patients and consistently demonstrates high sensitivity and specificity.

A routine screening procedure in oncology settings for early and appropriate identification of malnourished patients or patients at nutritional risk is an important part of disease management, and appropriate intervention may lead to improved outcomes and quality of life $[4,5,68]$. Ravasco et al. [5] showed in a prospective randomized controlled interventional trial in 75 head and neck cancer patients that personalized dietary counseling may prove beneficial, even having an effect on the final oncologic outcome.

\section{Conclusions}

The screening tools presented in this article are fast and easily applied, and all are validated in mixed populations and, to a certain extent, also in cancer patients. All the presented screening tools have been shown to be useful and to embody the principles of good nutritional screening described above. Experience shows that it is most important that cancer patients are screened. The choice of the appropriate screening tool is important, but the time needed to complete the screening process will always play a role in the hospital setting. Once patients at nutritional risk have been identified, a proactive and early nutritional approach should constitute an integral part of cancer treatment, with the intention of improving clinical outcome and quality of life and reducing health care costs. Furthermore, as shown in Table 1, there is evidence that certain nutritional screening tools can help to identify patients at higher risk for complications and mortality.

In an oncology population, the PG-SGA and the MST are the tools which have been best validated, but further research using larger sample sizes for this patient group is needed. The MST is quicker and easier to use than the PGSGA and can be completed by medical, nursing, dietetic, or administrative staff or by the patients or their family members. It should be pointed out that there are few studies that directly link the nutrition process to improved outcomes in this setting. Routine nutritional screening with validated tools can identify cancer patients at risk, but we need further research to evaluate the benefits of nutritional screening and support and their effect on outcomes.

Conflict of interest None to declare.

\section{References}

1. Fearon K, Barber M, Moses AG (2001) The cancer cachexia syndrome. Surg Oncol Clin N Am 10:109-126

2. Pirlich M, Schutz T, Norman K, Gastell S, Lubke HJ, Bischoff SC, Bolder U, Frieling T, Guldenzoph H, Hahn K, Jauch KW, Schindler K, Stein J, Volkert D, Weimann A, Werner H, Wolf C, Zurcher G, Bauer P, Lochs H (2006) The German hospital malnutrition study. Clin Nutr 25:563-572

3. Sorensen J, Kondrup J, Prokopowicz J, Schiesser M, Krähenbühl L, Meier R, Liberda M, EuroOOPS Study Group (2008) EuroOOPS: an international, multicentre study to implement nutritional risk screening and evaluate clinical outcome. Clin Nutr 27:340-349

4. Amaral TF, Antunes A, Cabral S, Alves P, Kent-Smith L (2008) An evaluation of three nutritional screening tools in a Portuguese oncology centre. J Hum Nutr Diet 21:575-583

5. Ravasco P, Monteiro-Grillo I, Marques Vidal PM, Camilo ME (2005) Impact of nutrition on outcome: a prospective randomized controlled trial in patients with head and neck cancer undergoing radiotherapy. Head Neck 27:659-668

6. Iff S, Leuenberger M, Sterchi A, Stanga Z (2008) Nutritional management study: screening part. Clin Nutr 3(supp11):154, Abstract

7. Marin Caro MM, Gomez Candela C, Castillo Rabaneda R, Lourenço Nogueira T, Garcia Huerta M, Loria Kohen V, Villarino Sanz M, Zamora Auñon P, Luengo Perez L, Robledo Saenz P, Lopez-Portabella C, Zarazaga Monzon A, Espinosa Rojas J, Nogues Boqueras R, Rodriguez Suarez L, Celaya Perez S, Pardo Masferrer J (2008) Nutritional risk evaluation and establishment of nutritional support in oncology patients according to the protocol of the Spanish Nutrition and Cancer Group. Nutr Hosp 23:458-468

8. Nozoe T, Kimura Y, Ishida M, Saeki H, Korenaga D, Sugimachi K (2002) Correlation of pre-operative nutritional condition with post-operative complications in surgical treatment for oesophageal carcinoma. Eur J Surg Oncol 28:396-400

9. Gupta D, Lammersfeld CA, Vashi PG, Burrows J, Lis CG, Grutsch JF (2005) Prognostic significance of subjective global assessment (SGA) in advanced colorectal cancer. Eur J Clin Nutr 59:35-40

10. Gupta D, Lis CG, Granick J, Grutsch JF, Vashi PG, Lammersfeld CA (2006) Malnutrition was associated with poor quality of life in colorectal cancer: a retrospective analysis. J Clin Epidemiol 59:704-709

11. Ottery FD (1994) Cancer cachexia: prevention early diagnosis und management. Cancer Pract 2:123

12. McWhirter JP, Pennington CR (1994) Incidence and recognition of malnutrition in hospital. BMJ 308:945-948

13. Gallagher-Allred CR, Voss AC, Finn SC, McCamish MA (1996) Malnutrition and clinical outcome: the case for medical nutrition therapy. J Am Diet Assoc 96:361-366

14. Correia MI, Waitzberg DL (2003) The impact of malnutrition on morbidity, mortality, length of hospital stay and costs evaluated through a multivariate model analysis. Clin Nutr 22:235-239

15. Dewys WD, Begg C, Lavin PT, Band PR, Bennett JM, Bertino JR, Cohen MH, Douglass HO, Engstrom PF, Ezdinli EZ, Horton J, Johnson GJ, Moertel CG, Oken MM (1980) Prognostic effect of weight loss prior to chemotherapy in cancer patients. Eastern Cooperative Oncology Group. Am J Med 69:491-497

16. Huhmann MB, Cunningham RS (2005) Importance of nutritional screening in treatment of cancer-related weight loss. Lancet Oncol 6:334-343

17. Unsal D, Mentes B, Akmansu M, Uner A, Oguz M, Pak Y (2006) Evaluation of nutritional status in cancer patients receiving radiotherapy: a prospective study. Am J Clin Oncol 29:183-188 
18. ASPEN Board Directors and the Clinical Guidelines Task Force (2002) Guidelines for the use of parenteral and enteral nutrition in adult and pediatric patients. JPEN J Parenter Enteral Nutr 26:1SA-138SA

19. Kondrup J, Allison SP, Elia M, Vellas B, Plauth M (2003) ESPEN guidelines for nutrition screening 2002. Clin Nutr 22:415-421

20. Elia M, Zellipour L, Stratton RJ (2005) To screen or not to screen for adult malnutrition? Clin Nutr 24:867-884

21. Green SM, Watson R (2005) Nutritional screening and assessment tools for use by nurses: literature review. J Adv Nurs 50:69-83

22. Ferguson M, Capra S, Bauer J, Banks M (1999) Development of a valid and reliable malnutrition screening tool for adult acute hospital patients. Nutrition 15(6):458-464

23. Powell-Tuck J, Hennessy EM (2003) A comparison of mid upper arm circumference, body mass index and weight loss as indices of undernutrition in acutely hospitalized patients. Clin Nutr 22:307312

24. Kyle UG, Genton L, Pichard C (2005) Hospital length of stay and nutritional status. Curr Opin Clin Nutr Metab Care 8:397-402

25. Ravasco P, Monteiro-Grillo I, Marques Vidal PM, Camilo ME (2004) Cancer: disease and nutrition are key determinants of patients' quality of life. Support Care Cancer 12:246-252

26. Malnutrition Advisory Group (MAG) (2000) MAG-guidelines for detection and management of malnutrition. British Association for Parenteral and Enteral Nutrition, Redditch

27. Stratton RJ, Hackston A, Longmore D, Dixon R, Proce S, Stroud M, King C, Elia M (2004) Malnutrition in hospital outpatients and inpatients: prevalence, concurrent validity and ease of use of the "Malnutrition Universal Screening Tool" ("MUST") for adults. Br J Nutr 92:799-808

28. Elia M (2003) The MUST report: nutritional screening of adults: a multidisciplinary responsibility. BAPEN (MAG), Maidenhead

29. Stratton RJ, King CL, Stroud MA, Jackson AA, Elia M (2006) 'Malnutrition Universal Screening Tool' predicts mortality and length of hospital stay in acutely ill elderly. Br J Nutr 95:325330

30. Kondrup J, Rasmussen HH, Hamberg O, Stanga Z (2003) Nutritional risk screening (NRS-2002): a new method based on an analysis of controlled clinical trials. Clin Nutr 22:321-336

31. Wenger C, Hischier T, Rhyner A, Iff S, Sterchi AB, Stanga Z (2008) Ernährungsmanagement: Einführung in zwei universitären Fachkliniken. Aktuel Ernaehr Med 33:296-301

32. Kondrup J, Johansen N, Plum LM, Bak L, Larsen IH, Martinsen A, Andersen HR, Bærnthsen H, Bunch E, Lauesen N (2002) Incidence of nutritional risk and causes of inadequate nutritional care in hospitals. Clin Nutr 21:461-468

33. Johansen N, Kondrup J, Plum LM, Bak L, Nørregaard P, Bunch E, Bærnthsen H, Andersen JR, Højlund Larsen I, Martinsen A (2004) Effect of nutritional support on clinical outcome in patients at nutritional risk. Clin Nutr 23:539-550

34. Guigoz Y, Vellas B, Garry PJ (1996) Assessing the nutritional status of the elderly: the mini nutritional assessment as part of the geriatric evaluation. Nutr Rev 54:59-65

35. Vellas B, Guigoz Y, Baumgartner M, Garry PJ, Lauque S, Albarede JL (2000) Relationships between nutritional markers and the mini-nutritional assessment in 155 older persons. J Am Geriatr Soc 48:1300-1309

36. Mini Nutritional Assessment. Forms available at http://www. mna-elderly.com

37. De Groot CP, van Staveren WA (2002) Survey in Europe on nutrition and the elderly, a concerted action. Undernutrition in the European SENECA studies. Clin Geriatr Med 18:699-708

38. Vells B, Guigoz Y, Garry PJ, Nourhashemi F, Bennahum D, Lauque S, Albarede JL (1999) The mini nutritional assessment (MNA) and its use in grading the nutritional state of elderly patients. Nutrition 15:116-122
39. Rubenstein LZ, Harker JO, Salvà A, Guigoz Y, Vellas B (2001) Screening for undernutrition in geriatric practice: developing the short-form mini-nutritional assessment (MNA-SF). J Gerontol A Biol Sci Med Sci 56:M366-M372

40. Bauer JM, Vogl T, Wicklein S, Trögner J, Mühlberg W, Sieber CC (2005) Comparison of the Mini Nutritional Assessment, Subjective Global Assessment, and the Nutritional Risk Screening (NRS 2002) for nutritional screening and assessment in geriatric hospital patients. Z Gerontol Geriatr 38:322-327

41. Vellas B, Villars H, Abellan G, Soto ME, Rolland Y, Guigoz Y, Morley JE, Chumlea W, Salva A, Rubenstein LZ, Garry P (2006) Overview of the MNA - its history and challenges. J Nutr Health Aging 10:456-463

42. Detsky AS, McLaughlin JR, Baker JP, Johnston N, Whittaker S, Mendelson RA, Jeejeebhoy KN (1987) What is subjective global assessment of nutritional status? JPEN J Parenter Enteral Nutr 11:9-13

43. Barbos-Silva MC, de Barros AJ (2002) Subjective global assessment: part 2. Review of its adaptations and utilization in different clinical specialties. Arq Gastroenterol 39:248-252

44. Ottery FD (1996) Definition of standardized nutritional assessment and interventional pathways in oncology. Nutrition 12:S15-S19

45. Persson C, Sjoden PO, Glimelius B (1999) The Swedish version of the patient-generated subjective global assessment of nutritional status: gastrointestinal vs. urological cancers. Clin Nutr 18:71-77

46. Bauer J, Capra S, Ferguson M (2002) Use of the scored patientgenerated subjective global assessment (PG-SGA) as a nutrition assessment tool in patients with cancer. Eur J Clin Nutr 56:779785

47. Isenring E, Bauer J, Capra S (2003) The scored patient-generated subjective global assessment (PG-SGA) and its association with quality of life in ambulatory patients receiving radiotherapy. Eur J Clin Nutr 57:305-309

48. Ravasco P, Monteiro-Grillo I, Vidal PM, Camilo M (2003) Nutritional deterioration in cancer: the role of disease and diet. Clin Oncol (R Coll Radiol) 15:443-450

49. Read JA, Crockett N, Volker DH, Mac Lennan P, Choy ST, Beale P, Clarke SJ (2005) Nutrition assessment in cancer: comparing the mini-nutrition assessment (MNA) with the scored patientgenerated subjective global assessment (PGSGA). Nutr Cancer 53:51-56

50. Kubrak C, Jensen L (2007) Critical evaluation of nutrition screening tools recommended for oncology patients. Cancer Nurs 30:E1-E6

51. Sungurtekin H, Sungurtekin U, Hanci V, Erdem E (2004) Comparison of two nutrition assessment techniques in hospitalized patients. Nutrition 20:428-432

52. Christensson L, Unosson M, Ek AC (2002) Evaluation of nutritional assessment techniques in elderly people newly admitted to municipal care. Eur J Clin Nutr 56:810-818

53. Kyle UG, Kossovsky MP, Karsegard VL, Pichard C (2006) Comparison of tools for nutritional assessment and screening at hospital admission: a population study. Clin Nutr 25:409417

54. Detsky AS, Smalley PS, Chang J (1994) The rational clinical examination. Is this patient malnourished? JAMA 271:54-58

55. Jeejeebhoy KN (1990) Assessment of nutritional status. Saunders, Philadelphia

56. Slaviero KA, Read JA, Clarke SJ, Rivory LP (2003) Baseline nutritional assessment in advanced cancer patients receiving palliative chemotherapy. Nutr Cancer 46:148-157

57. Thoresen L, Fjeldstad I, Krogstad K, Kaasa S, Falkmer UG (2002) Nutritional status of patients with advanced cancer: the value of using the subjective global assessment of nutritional status as a screening tool. Palliat Med 16:33-42 
58. Laky B, Janda M, Cleghorn G, Obermair A (2008) Comparison of different nutritional assessments and body-composition measurements in detecting malnutrition among gynecologic cancer patients. Am J Clin Nutr 87:1678-1685

59. Weimann A, Braga M, Harsanyi L, Laviano A, Ljungqvist O, Soeters P (2006) ESPEN guidelines on enteral nutrition: surgery including organ transplantation. Clin Nutr 25:224-244

60. Ferguson ML, Bauer J, Gallagher B, Capra S, Christie DR, Mason BR (1999) Validation of a malnutrition screening tool for patients receiving radiotherapy. Australas Radiol 43(3):325327

61. Bauer J, Capra S (2003) Comparison of a malnutrition screening tool with subjective global assessment in hospitalised patients with cancer-sensitivity and specificity. Asia Pac J Clin Nutr 12 (3):257-260

62. Roulston F, McDermott R (2009) Comparison of three validated nutritional screening tools in the oncology setting. Proc Nutr Soc 67:E260
63. Schwegler I, von Holzen A, Gutzwiller JP, Schlumpf R, Mühlebach S, Stanga Z (2010) Nutritional risk screening predicts complications on colorectal cancer surgery? Br J Surg 97:92-97

64. Bozzetti F (2009) Screening the nutritional status in oncology: a preliminary report on 1000 outpatients. Support Care Cancer 17:279-284

65. Gupta D, Lammersfeld CA, Vashi PG, Dahlk SL, Lis CG (2008) Can subjective global assessment of nutritional status predict survival in ovarian cancer? J Ovarian Res 1(1):5

66. Schiesser M, Müller S, Kirchhoff P, Breitenstein S, Schäfer M, Clavien P-A (2008) Assessment of a novel screening score for nutritional risk in predicting complications in gastro-intestinal surgery. Clin Nutr 27:565-570

67. Toliusiene J, Lesauskaite V (2004) The nutritional status of older men with advanced prostate cancer and factors affecting it. Support Care Cancer 12:716-719

68. Von Mayenfeldt M (2005) Cancer-associated malnutrition: an introduction. Eur J Oncol Nurs 9:S33-S34 